\title{
Correction to: 8th European Medical and Biological Engineering Conference
}

Tomaz Jarm, Aleksandra Cvetkoska, Samo Mahnič-Kalamiza, and Damijan Miklavcic

Correction to:

T. Jarm et al. (Eds.): 8th European Medical and Biological

Engineering Conference, IFMBE Proceedings 80, https://doi.org/10.1007/978-3-030-64610-3

In the original version of the book, the following corrections have been incorporated: In Chapter 48, one of the author's street number has been changed from "Via Cardarelli 8 " to "Via Cardarelli 9".

In Chapter 76, one of the chapter author's surname has been changed from "Federica Amintrano" to "Federica Amitrano".

The chapter and book have been updated with the changes.

The updated version of these chapters can be found at https://doi.org/10.1007/978-3-030-64610-3_48

https://doi.org/10.1007/978-3-030-64610-3_76

(C) Springer Nature Switzerland AG 2021

T. Jarm et al. (Eds.): EMBEC 2020, IFMBE Proceedings 80, p. C1, 2021.

https://doi.org/10.1007/978-3-030-64610-3_131 